\title{
Pensar la vida común desde los feminismos
}

\author{
Thinking the common life from the feminisms
}

SILVIA L. GIL*

\begin{abstract}
Resumen: La insistencia de las filosofías de la segunda mitad del siglo veinte en los discursos, la contingencia de los significantes y la crítica a los universales parecería precipitarnos a la pospolítica, un tiempo donde la transformación se declara imposible. Sin embargo, las prácticas feministas que surgen en el contexto de la llamada crisis del sujeto del feminismo, marcado por la dispersión y las nuevas formas de poder contemporáneas, son una oportunidad para pensar otra política no esencialista ni unitaria. Esta otra política, en la que se juegan otras maneras de conocer y ser, pasa por el reconocimiento y la construcción de una política de lo común.

Palabras clave: Nuevos Feminismos, Diferencia, Postestructuralismo, Crisis del Sujeto Feminista, Política de lo Común.
\end{abstract}

\begin{abstract}
Summary: The postmodern insistence on discourses, on the contingency of signifiers, or on the critique of universals characteristic of latecentury philosophies would seem to precipitate us into postpolitics, a time when transformation is declared impossible. However, the new feminisms that arise in the context of the so-called crisis of the subject of feminism, marked by dispersion and the new contemporary forms of power, are an opportunity to think of another non-essentialist and unitarian politics. This other policy involves the recognition and construction of a common policy.

Key words: New Feminisms, Difference, Poststructuralism, Crisis of the Feminist Subject, Politics of the common.
\end{abstract}

\section{Crisis del sujeto del feminismo ${ }^{1}$}

Desde la década de los 90, asistimos a la proliferación de una serie de debates que han insistido en la importancia de interrogar uno de los pilares de las luchas feministas: la categoría «Mujer». Aunque afirmar la crisis del sujeto del feminismo que tiene lugar con esta crítica parece ser una fórmula recurrente -que, según las críticas, sería producida desde

Recibido: 12/02/2017. Aceptado: 12/07/2017.

* Profesora/Investigadora de Filosofía de la Universidad Iberoamericana de la Ciudad de México. Correo: silvia@sindominio.net Líneas de investigación: filosofía contemporánea, teoría y filosofía feministas, pensamiento político, subjetividad y cambio social. Publicaciones: Gil, Silvia L. (2014), «Ontología de la precariedad en Judith Butler. Repensar la vida en común», Endoxa, Series Filosóficas, n 34, Madrid: UNED. pp. 287-302; y «Debates en la Teoría Feminista Contemporánea: Sujeto, Ética y Vida en Común» (2014), Quaderns de Psicologia, Vol. 16, nº, Barcelona.

1 Este texto es producto de la estancia posdoctoral en el Colegio de Filosofía de la Facultad de Filosofía y Letras de la UNAM como becaria del Programa de Becas Posdoctorales 2013 de la Dirección General de Asuntos del Personal Académico. 
posiciones posmodernas y relativistas, dejando al feminismo sin alternativa-, es importante dirigir la mirada hacia una serie de prácticas que acompañan este fenómeno y que muestran cómo se renuevan los sentidos e imaginarios de las políticas de nuestro tiempo. Hay que tener en cuenta que esta crisis no tiene solo un carácter negativo: por una parte, es cierto que desde la segunda mitad de los 80's aumenta la dificultad de enunciación colectiva; pero, por otra, esta crisis posibilitará que se reinventen las antiguas formas de organización. Si las feministas desafiaron la teoría marxista, exigiendo una mirada encarnada en la diferencia sexual y cuestionando la «lucha de clases», formulada a partir de un sujeto uniforme y masculinizado (desde el que las problemáticas «femeninas» son consideradas subsidiarias de la esfera económica); progresivamente, desde el interior de los mismos feminismos, se interrogaron en un sentido parecido los presupuestos implícitos en la identidad femenina -tanto sus pretensiones de universalidad como su carga metafísica-. Las discusiones en la teoría feminista contemporánea irán en la línea de repensar dichos presupuestos².

El marco de comprensión imperante hasta entonces de las desigualdades de género lo ofrecía la diferencia sexual. En él, masculino y femenino se consideran identidades uniformes opuestas entre sí de manera asimétrica. Sin embargo, este esquema, además de ser criticado por su espesura ontológica (¿qué cualidades incluimos en lo «femenino» y cuáles excluimos de manera implícita?, ¿cómo pensar los complejos y contradictorios procesos de construcción corporal desde categorías inamovibles?), perderá capacidad para explicar la heterogeneidad de las subjetividades políticas emergentes. Al respecto, la teoría de género producirá un interesante giro, abriendo la diferencia sexual a sus articulaciones sociales e históricas concretas, visibilizando aquellos cuerpos que desbordan las normas de género, así como replanteando la complicidad de las identidades con el poder y distanciándose de la rigidez de una diferencia excesivamente estática. Según Joan Scott, «al insistir en las diferencias fijas [...], las feministas contribuyen al tipo de pensamiento al que tratan de oponerse» ${ }^{3}$. Por este motivo, la diferencia sexual no puede ser un punto de partida neutro; en todo caso, como dice Judith Butler, constituye una pregunta, una pregunta fundamental para la misma investigación feminista:

La diferencia sexual no es un hecho dado, no es una premisa, no es una base sobre la cual se pueda construir el feminismo; no es aquello con lo que ya nos hemos encontrado y que llegamos a conocer; más bien es la cuestión que provoca la investigación feminista, es algo que no puede ser del todo expuesto, que desestructura la gramática de la afirmación y que persiste, de forma más o menos permanente, como algo a lo que interrogar ${ }^{4}$.

En este sentido, se trata de repensar las identidades y, desde ahí, la política de la identidad dominante en los movimientos del siglo XX. En esta discusión, se citan planteamientos de distintas corrientes: postestructualistas, desde donde se dibuja una ontología de la diferen-

2 El libro editado por Joan Scott y Judith Butler recoge buena parte de estos importantes debates: Butler, J. y Scott, J. (eds.) (1992), Feminist therize the political, New York, London: Routledge.

3 Scott, J. W. (1996), «El género, una categoría útil para el análisis histórico», en Lamas, M. (comp.) (2013), El género. La construcción cultual de la diferencia sexual, México: PUEG/UNAM, pp. 265-302, p. 286.

4 Butler, J. (2004/2006), Deshacer el género, Barcelona: Paidós, pp. 252-253. 
cia $^{5}$; psicoanalistas, con su preocupación por la sexualidad y el sujeto ${ }^{6} ; \mathrm{y}$, por supuesto, feministas, que resituarán la importancia de las diferencias, el cuerpo y el género para interpretar los órdenes simbólico y socioeconómico. Y tiene lugar al calor de una inquietud política: ¿Es posible la transformación sin categorías fuertes que la sustenten? Dicho de otra manera: ¿Cómo conciliar las implicaciones de la deconstrucción del sujeto con las exigencias para resistir al poder contemporáneo? La insistencia posmoderna en los discursos, en la contingencia de los significantes o en la crítica a los universales parecería precipitar a la pospolítica $^{7}$, donde solo habría lugar para confirmar lo dado, pero no para su transformación. Sin embargo, veremos que las prácticas feministas que surgen al mismo tiempo que este debate, a las que podemos referirnos como nuevos feminismos, ofrecen claves fundamentales para pensar otra política cuando las diferencias son condición inherente de nuestro mundo.

\section{El sujeto Mujer en la Segunda Ola en el feminismo español}

Para profundizar en las dimensiones concretas del problema de la identidad, es interesante situarse de manera momentánea en el caso del feminismo español, donde en los años noventa surgen una serie de prácticas novedosas. ¿Por qué son novedosas? ¿En qué sentido producen una ruptura respecto a las experiencias anteriores y procuran algo nuevo que pensar? Desde 1975, la Plataforma de Organizaciones Feministas del Estado español funcionó como paraguas de las distintas agrupaciones que se organizaban a lo largo de todo el país: fueron años de agitación en las calles, de marchas y de movilizaciones al calor de las luchas antifranquistas, vecinales y obreras. Las reivindicaciones adquirían sentido en el ambiente represivo de la dictadura y de los años inmediatamente posteriores; la anticoncepción, el aborto, la prostitución o el adulterio estaban penados, por lo que muchas mujeres se encontraban presas en las cárceles femeninas. Ni siquiera existía el derecho al divorcio. Esta situación hacía que movilizarse fuese arriesgado, pero también generaba una idea compartida de resistencia.

En este contexto, ¿cuáles eran los presupuestos político-filosóficos feministas de aquellos años? El marxismo, referencia ineludible de aquella época, influía decisivamente. Por una parte, el movimiento se definirá en torno a la categoría «Mujer» (se dirá: «Mujer, rompe tus cadenas»), que se concibe como universal, en la medida en que se le adjudica la capacidad de representar a todas las mujeres. En El Segundo Sexo, Simone de Beauvoir desarrolló la idea de que en cada mujer concreta habita la Mujer con mayúscula, escindiendo su ser. Ese universal es una construcción social que homogeneiza la experiencia femenina; experiencia que, además, no es elegida. Por ello, Beauvoir argumenta que a las mujeres se les niega lo más esencial de la existencia humana, la posibilidad de singularizarse, de construir un camino propio ${ }^{8}$. De este modo, la idea «Mujer» será de vital importancia: permitirá nombrar

5 La lectura filosófica de Gilles Deleuze, Michel Foucault y Jaques Derrida resulta clave al respecto.

6 Flax, J. (1990/1995), Psicoanálisis y feminismo. Pensamientos fragmentarios, Madrid: Cátedra.

7 En este volumen se recogen varios ensayos críticos con el feminismo de lo «post» con la hipótesis de que se debilita el feminismo: Tubert, S. (ed.) (2003), Del sexo al género. Los equívocos de un concepto, Valencia: Universidad de Valencia.

8 Beauvoir, S. (1949/1989), El segundo sexo. I. Los hechos y los mitos. II. La experiencia vivida, Buenos Aires: Siglo Veinte. 
la opresión, invisible en las distintas esferas de la vida humana, y articular simbólicamente la lucha. Así, «Mujer» se convierte en el sujeto del feminismo de la Segunda Ola9 . Para las feministas de la igualdad, adquiere la forma de un sujeto político y, para las de la diferencia, la de un sujeto ontológico, irreductible. En el primer caso, el cuerpo se neutraliza y el género se proyecta de manera general sobre todas las mujeres; en el segundo, el género se identifica con una esencia compartida, que se funda en el cuerpo-sexo-biológico del que se desprenderá un único significado. Uno hará del género una esencia social y otro una esencia ontológica ${ }^{10}$, pero ambas posturas presuponen una identidad que determina su destino.

Desde esta óptica, puede entenderse mejor el siguiente presupuesto que opera en ese momento: existe un sistema de dominación patriarcal monolítico cuyos efectos comparten todas las mujeres, la opresión es experimentada de manera similar (y, según explica Simone de Beauvoir en el Segundo Sexo, ésta es mayor que ninguna otra). La necesidad de nombrar la opresión femenina desplazará otras diferencias como las derivadas de posiciones de clase, raza o sexo; diferencias que, sin embargo, más tarde, resultarán ineludibles. Aunque en los textos clásicos de los años setenta como La dialéctica del sexo, de Sulamith Firestone ${ }^{11}$, o La politica sexual, de Kate Millet, exista una preocupación directa por las distintas variables de opresión, la primera, como ha señalado Angela Davis ${ }^{12}$, interpreta el racismo como una continuidad del sexismo y la segunda sugiere que el sexismo es una opresión más primaria que cualquier otra ${ }^{13}$. De este modo, en este momento, las diferencias son consideradas, pero sobre la base de un una opresión común.

Por eso, la pregunta que muchas se hacían en aquella época tenía que ver con comprender el origen de dicha dominación: mientras que algunas lo explican enfatizando la sexualidad, otras lo hacen a partir de los aspectos materiales (en el sentido de explicar cuál es el lugar de reproducción de la desigualdad: si para los hombres es la fábrica, para las mujeres será el hogar $)^{14}$. Las primeras priorizan modificar las estructuras simbólicas y culturales y las segundas las estructuras económicas e institucionales. Esto dio lugar a un intenso debate sobre la posición de las mujeres en el sistema socioeconómico (no tanto en relación a las diferencias de clase entre mujeres, sino a los vínculos entre aquél y el sexo) y sus articulaciones en el capitalismo, que se tradujo en una profunda indagación en torno al trabajo doméstico en los 70's, fundamental para reconstruir un análisis específico de las relaciones de poder, así como las posibilidades y límites de la teoría marxista ${ }^{15}$. Esto determinará otro

9 Hay quienes ven en ese momento no la Segunda Ola del movimiento, sino la tercera (de modo que actualmente estaríamos en la cuarta). Sin embargo, consideramos que se trata de una lectura que se adapta más a la realidad anglosajona que a otras como la española o la latinoamericana donde los nuevos discursos y prácticas cobran más fuerza en la mitad de los noventa y principio de los dos mil y no en la segunda mitad de los ochenta como en EE.UU.

10 Casado, E. (2003), «La emergencia del género y su resignificación en tiempos de lo "post”», Foro Interno. Anuario de teoría política, $\mathrm{n}^{\circ}$ 3, pp. 41-66.

11 Firestone, S. (1976), La dialéctica del sexo. En defensa de la revolución feminista, Barcelona: Kairós.

12 Davis, A.(1981/2005), Mujeres, raza y clase, Madrid: Akal.

13 Millet, K. (1970/1995), Política Sexual, Madrid: Cátedra, p. 70.

14 Pineda, E., Oliva, M. y Uría, P. (1985), Polémicas Feministas, Madrid: Revolución; y VVAA. (1977), Aportaciones a la cuestión femenina, Madrid: Akal.

15 Heidi Hartmann había sido contundente al afirmar en «Un matrimonio mal avenido: hacia una unión más progresiva entre marxismo y feminismo» que «las categorías marxistas, como el mismo capital, son ciegas en lo referente al sexo». Z. Eisenstein, por su parte, también había declarado la insuficiencia de estas herramientas y, 
de los presupuestos en esos años: se trata de un movimiento de masas. Esto no se refiere solo a la cantidad de cuerpos que participan, que se hacen visibles, sino más bien al peso simbólico del movimiento: se forma una ola que arrastra a quienes lo desean a su paso y tiene lugar una identificación amplia con fuerza y efectos en la capacidad de negociación y disputa. En este escenario, pese a diferencias o matices, existe acuerdo en la necesidad de una lucha unitaria para la que se requieren estructuras aglutinantes (en el caso del Estado español, este papel lo cumplirá la mencionada Plataforma de Organizaciones Feministas del Estado español, que en los noventa perderá esta función y entrará en crisis ${ }^{16}$. Si bien estos presupuestos -sujeto unificado, opresión compartida, movimiento masivo y centralismo organizativo- permanecerán en la primera mitad de los ochenta, las transformaciones socioeconómicas, ensayadas en ese momento en buena parte del planeta, propiciarán poco a poco que se desdibujen.

\section{Nueva lógica del poder contemporáneo}

En los noventa, el movimiento como referente colectivo irá desapareciendo. El despegue del neoliberalismo y la reestructuración del mercado de trabajo impondrán la flexibilidad y la precariedad como normas sociales. La extensión de esta lógica como mecanismo de sometimiento a nuevas capas de la población (lo que algunas han llamado feminización del trabajo ${ }^{17}$ ), influirá en el paso de una experiencia social uniforme, basada en estructuras fijas -familia, ejército, escuela, hospital, Estado-, a una experiencia social diversificada, donde la desestructuración no muestra solo una cara negativa, sino también la posibilidad de gozar de ciertas libertades. Para muchas, en un primer momento, esto supone romper con el esquema social mujer-ama de casa/hombre-proveedor del pan propio del fordismo: empiezan a viajar, acceden a la universidad, al mercado laboral, etc., y aparecen otros modelos de vida, sexualidad y convivencia. Posteriormente, la flexibilidad se traducirá en obligación y la precariedad en intensificación de una nueva pobreza. Las mujeres entonces verán que las tareas del hogar siguen en sus manos (haciendo que la jornada se multiplique en el contexto de la crisis de $\operatorname{cuidados}^{18}$ ), y que su acceso al mercado laboral no

en el contexto español, feministas como Lidia Falcón se lanzaron a analizar el modo de producción doméstico introduciendo la idea de que las mujeres constituyen en sí mismas una clase social: Hartmann, Heidi (1980), «Un matrimonio mal avenido: hacia una unión más progresista entre marxismo y feminismo» en Eisenstein, Z. R. (1980), Patriarcado feminista y feminismo socialista, Madrid: Siglo XXI; Falcón, L. (1981), La razón feminista. La mujer como clase social y económica, el modo de producción doméstica, Barcelona: Fontanella.

16 Para un estudio amplio de la historia del movimiento feminista en España hasta 1985 véase Agustín Puerta, M. (2003), Feminismo: Identidad personal y lucha colectiva (Análisis del movimiento feminista español en los años 1975 a 1985), Granada: Universidad de Granada.

17 Precarias a la Deriva (2004), A la deriva por los circuitos de la precariedad femenina, Madrid: Traficantes de Sueños.

18 La feminista Sira del Río explica la importancia de la crisis de cuidados: «Efectivamente, el modelo mediante el cual se resolvían las necesidades de cuidados se tambalea. Las mujeres, que habían dedicado todo su tiempo y energías a este trabajo no remunerado, se empiezan a incorporar masivamente a un mercado laboral masculino, cuya estructura está diseñada para personas que no tienen que cuidar de nadie. De este modo, la tensión entre la lógica del mercado y la lógica del cuidado emerge con gran intensidad y las mujeres empiezan a experimentar esta tensión en su propio cuerpo, que se convierte en lugar de batalla entre las exigencias de uno y otro escenario. Este hecho, que no pasa desapercibido para casi nadie, pretende solventarse con políticas y leyes denomina- 
se materializa en derechos. La reivindicación clásica de acceso al empleo para recuperar autonomía e independencia económica deberán entonces ser revisadas. A todo esto se suma que las formas de dominio se sofistican: donde antes solo había represión y control ahora hay libertad de consumo y nuevas formas de sujeción, basadas en exigencias corporales cada vez más intensas, la moda, la disciplina impuesta por las corporaciones, la adaptación a ritmos vertiginosos, la capacidad para mantenerse siempre conectada... Esta nueva situación desplaza las reivindicaciones de lo urgente, defensa de derechos básicos, a las de lo posible, que no tienen que ver solo con resistir, sino con nombrar realidades insertas en los nuevos flujos de poder, como el caso de las mujeres migrantes en las ciudades globales. Además, desde la década de los ochenta se produce otro fenómeno: la extensión del feminismo de Estado. Éste modificará radicalmente el mapa del poder y resituará a los movimientos no frente, sino en el interior de su misma lógica. El eco de los discursos de igualdad, las estrategias legalistas o las mismas dinámicas de prioridades y tiempos impuestas por las instituciones generarán un desequilibrio entre los asuntos visibles y los no visibles. Se producirá una disputa en relación a las visibilidades. La brecha entre los feminismos autónomos y los discursos sobre la igualdad será más notable ${ }^{19}$.

Todos estos factores, acompañados por un marco de pensamiento que profundiza en la crítica filosófica de los fundamentos que estructuraron la realidad desde la época moderna -Sustancia, Yo, Sujeto, Dios-, y que propiciará esquemas más flexibles, contribuyen a uno decisivo: se expresan las diferencias entre mujeres. Estas diferencias no son abstractas, se concretan en distintos intereses, inquietudes y prioridades, lo que se traduce en un debate vivo, encarnado. Con todo, en los años noventa, se pasa del problema de la diferencia entre hombres y mujeres al problema de la diferencia en general: la diferencia no entendida solo como oposición externa entre identidades pre-constituidas, sino como aquello que internamente difiere de sí. Dicho de otra manera: la diferencia como rasgo inherente del ser. La pregunta que se moviliza entonces es: ¿Cómo dar cuenta de la singularidad de los cuerpos sin dejar de mostrar que existen experiencias de opresión compartidas? ¿Cómo hacer análisis generales que no asfixien una realidad múltiple? El sujeto Mujer, entendido como identidad unívoca, estable, fuerte, entra en crisis; y, con ello, el modelo organizativo mencionado. En este contexto, surgen nuevas prácticas que forman una constelación junto a otros movimientos que dese los márgenes tratan de reinventar el sentido de la política más allá de los cauces convencionales de representación institucional. Aquí, de la mano de importantísimos referentes como el zapatismo, pero también a caballo de la estela dejada por el 68 , los nombres de la política serán sustituidos: representación por autonomía, centralización por red, unidad por diversidad, gestión y administración por creación e

das de "conciliación". Pero difícilmente puede conciliarse lo irreconciliable. En este caso, la centralidad de los mercados en la organización social se traduce en la priorización absoluta de los imperativos del mercado laboral frente a cualquier otro argumento. Sus necesidades productivas organizan el tiempo social y son inapelables frente a las necesidades de cuidados». Del Río, Sira, «La crisis de los cuidados: precariedad a flor de piel», Rebelión, 2004. Disponible en https://www.rebelion.org/hemeroteca/economia/040308sira.htm

19 Para un análisis sobre la institucionalización en el feminismo español en el contexto de la transición democrática, véase Gil, Silvia L. (2011), Nuevos feminismos. Sentidos comunes en la dispersión, Madrid: Traficantes de Sueños, pp. 102-124. 
invención, deber por deseo, vanguardia por caminar preguntando... Cabe pensar que hoy aún estamos experimentando las consecuencias históricas de este cambio de paradigma.

\section{Nuevas prácticas feministas}

Estos cambios hay que entenderlos en un marco socioeconómico más amplio en el que las condiciones de reproducción de la existencia empeoran a escala global (la crisis de reproducción se intensifica en los países del Sur y se extiende al Norte), hasta el punto de evidenciar una crisis estructural del mismo sistema capitalista. Un sistema que, como dice la economista Amaia Pérez Orozco, ataca la vida ${ }^{20}$. No se trata de una crisis que pueda solucionarse con un parche, no es solo un accidente en el buen desarrollo del neoliberalismo; se trata de una crisis estructural, de los propios fundamentos que la sostienen y que, como explica Bolívar Echevarría, es consustancial a la modernidad ${ }^{21}$. Las feministas argumentan que esos valores estructuran además el vínculo entre violencia, modernidad, capitalismo y masculinidad $^{22}$. Pero se trata también de una crisis de representación del sistema político, del sistema de partidos y de la democracia parlamentaria. Esta crisis, que expresan los movimientos autónomos desde los ochenta llegará a su cumbre con la explosión de la Primavera Árabe en 2011 y la ola de movilizaciones posteriores -15M español, YoSoy132 mexicano, los estudiantes chilenos, el movimiento Passe Livre de Brasil, Occupy Wall Street..._- ${ }^{23}$. En esta crisis, se hace evidente la brecha cada vez mayor entre la ciudadanía y los lugares de toma de decisión que determinan el rumbo del mundo -organismos supranacionales, mercados financieros, etc.-. Por tanto, nos encontramos antes una doble crisis: crisis estructural del capitalismo, de sus valores fundantes, y crisis de representación.

En este sentido, puede afirmarse que las nuevas prácticas feministas surgen en un contexto que es cada vez más hostil a la vida y que, al mismo tiempo, impone enormes dificultades para pensar lo político: no se cuentan con grandes relatos como el marxista que permitan saber con anterioridad a la propia acción qué hacer. Esta dificultad, expuesta con claridad por Ernesto Laclau y Chantal Mouffe en Hegemonia y estrategia socialista en $1985^{24}$, tiene un aspecto positivo en la medida en que abre la puerta a una política antiesencialista. Un antiesencialismo que se decanta en una vertiente no solo discursiva (en la que se apoya la teoría

20 Orozco, A. (2014), Subversión feminista de la economía. Apuntes para una reflexión sobre el conflicto capitall vida, Madrid: Traficantes de Sueños.

21 «[...] es una crisis de la calidad misma de la vida civilizada, una crisis que no sólo es económica y política, no es sólo una crisis de los estados nacionales y sus soberanías sino que está afectando y que lleva afectando mucho tiempo a los usos y costumbres de todos órdenes: sexuales, culinarios, habitacionales, cohabitacionales Echeverría, B. (2010), «Crisis civilizatoria», Estudios Ecológicos, Crisis Financiera o Crisis Civilizatoria, $\mathrm{n}^{\circ} 6$, Quito, pp. 3-10, p.5.

22 Silvia Federici explica el profundo vínculo que existe entre el capitalismo, el exterminio de cientos de miles de mujeres en la caza de brujas y la forma que adquiere la dominación masculina en la modernidad. Federici, S. (2011), El Calibán y la bruja, Madrid: Traficantes de Sueños.

23 Para comprender la relación entre autonomía, zapatismo, movimiento de resistencia global y las movilizaciones en red más recientes véase el imprescindible trabajo de Guiomar Rovira. Por ejemplo: «De las redes a las plazas: la web 2.0 y el nuevo ciclo de protestas en el mundo», Acta Sociológica, Volumen 62, 2013, UNAM, México, pp. 105-134.

24 La traducción al español es posterior: Laclau E. y Mouffe, Ch. (1987), Hegemonia y estrategia socialista, Madrid: Siglo XXI. 
de la hegemonía populista), sino también experimental y encarnada (que tiende a considerar las prácticas micropolíticas e inmanentes indispensables en los procesos de cambio) ${ }^{25}$. En esta segunda línea, se incluyen las prácticas feministas mencionadas, que desplazarán los presupuestos de la Segunda Ola. Por un lado, se cuestiona que exista un único sistema de opresión, el patriarcado, entendido como una sustancia monolítica, fija, y se argumenta que existen diferentes sistemas de opresión entrelazados entre sí. Los análisis sobre el poder de Michel Foucault contribuyeron a interpretarlo como un entramado de relaciones encarnadas en el campo social. Por otra parte, algunas autoras defenderán que nos encontramos ante un capitalismo patriarcal racialmente estructurado ${ }^{26}$; o, como sostiene Donna Haraway, ante una Cosa Escandalosa ${ }^{27}$. También se debate que exista una única experiencia de lo femenino: se descubren la complejidad y la multiplicidad inherentes a la identidad, asumiendo una idea menos estática, más dinámica, de las relaciones de poder y de sus vínculos con el sujeto ${ }^{28}$. Por último, se replanteará la unidad del propio movimiento feminista: se cuestionan las pretensiones, universalistas y totalizantes, de representar a todas las mujeres bajo la figura o la idea de la Mujer. Los feminismos periféricos criticarán los gestos que tratan de hablar en nombre de todas las mujeres (de las indígenas, de las trabajadoras sexuales, de las migrantes, etc.). Surgen pequeñas organizaciones muy desconectadas entre sí, que no buscan alcanzar el poder y que insisten en dotarse de sus propias herramientas, saberes y discursos sin necesidad de formalismos ni directrices externas. Y que no piensan en términos de jerarquía, sino de horizontalidad, multiplicación y contagio. La pregunta que surgirá aquí es: ¿cómo seguir hablando de política en este contexto? En otras palabras: ¿Qué política se puede con un sujeto que ya no es Uno?

\section{Política de lo común}

Por tanto, el contexto de la globalización está marcado por las diferencias y la dispersión. ¿Cuáles son las estrategias organizativas que se han puesto en marcha desde los feminismos? A grandes rasgos, pueden señalarse dos: esencialismo estratégico y organización en red. La primera, en el sentido de Gayatri Spivak, adquiere la forma de uniones temporales -la unidad, la categoría Mujer- para acciones políticas concretas ${ }^{29}$. La segunda se hizo especialmente relevante en el movimiento de resistencia global: la percepción de los movimientos a escala planetaria propició la creación de redes o alianzas en las que sin asumir una nueva

25 Una discusión desde la perspectiva micropolítica se encuentra en: VV.AA. (2005), Una Política de los Cuerpos, cuadernillo $n^{\circ} 1$, Área Cuerpo y comunicación de la Facultad de Ciencias Sociales de la Universidad de Buenos Aires (disponible en: https://issuu.com/areadecuerpoycomunicacion/docs/cuadernillo_web_)

26 Bhavnani, K. y Coulson, M., «Transformar el feminismo socialista. El reto del racismo», en VVAA. (2004), Otras inapropiables. Feminismos desde las fronteras, Madrid: Traficantes de sueños, pp. 51-62, p. 60. En el prólogo colectivo del libro, elaborado por la Escalera Karakola se señala: «nosotras añadiríamos heteropatriarcal».

27 Dice Donna Haraway: «[...] patriarcado capitalista blanco (¿de qué otro modo podríamos llamar a esa Cosa escandalosa?) que transforma todo en un recurso apto para ser apropiado [...]», Haraway, Donna (1991/1995), Ciencia, cyborg y mujeres, la reinvención de la naturaleza, Madrid: Cátedra, p. 340. Pero es Amaia Pérez Orozco quien retoma esta idea de Haraway para expresar esta compleja realidad.

28 La influencia de los trabajos de Foucault en este sentido será clave. Sobre todo Foucault, Michel (1987), Historia de la sexualidad. 1. La voluntad de saber, Madrid: Siglo XXI.

29 Spivak, G. (1987), In Other Worlds. Essays in Cultural Politics, Methuen, Routledge: New York. 
identidad se trabajaba de manera interconectada. Pese a que ambas estrategias son especialmente útiles como punto de partida en tanto que consideran una realidad de diferencias, se encuentran con el siguiente escollo: son estrategias que presuponen sujetos formados políticamente, personas que ya están organizadas o comparten ciertos códigos entre sí; y, por tanto, conducen a un modelo de articulación entre organizaciones políticas. Pero, ¿qué ocurre con las personas que no participan en éstas, más si cabe en un momento histórico en el que las estructuras políticas se encuentran en crisis y el conflicto entre capital y vida, entre poder y condiciones de reproducción de la existencia, se intensifica? En este sentido, parecería que hay un nudo en relación a la identidad que no termina de romperse. Aquí es donde aparece la necesidad de pensar desde los parámetros de una política de lo común. ¿En qué consistiría ésta?

La política de lo común ya no trataría de sujetos únicos -como en el feminismo de la Segunda Ola-, ni tampoco múltiples -como en el marco de la explosión de las diferencias, comprendidas como micro-identidades-, sino que, en un sentido distinto, procuraría abrir procesos que puedan interpelar a diferentes; procesos desde los que dar cuenta, nombrar y elaborar aquello que, aunque de manera diversa, se está viviendo, a fuerza de las imposiciones neoliberales a escala planetaria, de manera común. Desgraciadamente, la extensión del despojo de los bienes comunes, la mercantilización de los servicios, la vida como posible desecho del capitalismo, la violencia como ejercicio estructural, la distribución diferencial de los cuerpos que importan y los que no, la precariedad e incertidumbre como normas o la desestructuración de los límites sociales (que se traduce en estructuras polimorfas donde las instituciones del Estado se confunden con paramilitares, policía o narcotraficantes ${ }^{30}$ ) producen experiencias similares en distintas partes del mundo: las condiciones de pobreza, exclusión y violencia se extienden a pasos agigantados por el cuerpo social. Hoy, a tenor de, entre otras cosas, la crisis de refugiados sirios en Europa, los lugares seguros parecen haberse extinguido.

Pero esta inseguridad no tiene solo un carácter externo, también se interioriza como sentido concreto de vivir. El paradigma del capitalismo contemporáneo se desarrolla a través de un ideal de independencia que afirma tres cosas. La primera: que ser tiene la forma de una sustancia preconcebida y cerrada sobre sí, independiente de las alteridades que la sostienen y atraviesan. La segunda: la vida es un proyecto individual que nada tiene nada que ver con lo colectivo: se produce una expropiación primaria del pensamiento de lo común. Y la tercera: la vida no necesita ser cuidada, se le asigna la cualidad de ser autosuficiente en el plano físico y emocional, contribuyendo a invisibilizar el trabajo que la sostiene. Esta premisa solo se hace posible en la medida en que el conjunto de tareas que posibilitan la vida cotidianamente son desvalorizadas. Como han sostenido las feministas marxistas, el trabajo doméstico y de cuidado deviene invisible, se privatiza y es feminizado con el objeto de explotarlo de manera gratuita ${ }^{31}$.

Sin embargo, en el desarrollo de la vida, se producen fricciones y crisis que cuestionan la validez de este ideal; lo cuestionan no desde la teoría, sino como vivencia corporal, ten-

30 Segato, R. (2006/2013), Las nuevas formas de la guerra y el cuerpo de las mujeres, Buenos Aires: Tinta Limón.

31 Como explica Amaia Orozco, esta explotación se produce a escala global: las migraciones Sur-Norte o campociudad generan flujos de cuidados que sostienen la vida a escala planetaria, pero que, además de no ser reconocidos, son fuente de desigualdad, mostrando que estamos en un sistema que es esencialmente injusto. 
sión cotidiana y malestar del conflicto entre las exigencias de acumulación capitalista (el beneficio por encima de todo) y las necesidades vitales (imposibles de resolverse cuantificando costes o sometiéndolas a un fin externo). Aquí, la verdad del ideal de independencia se desmorona, se pone en entredicho, sus preceptos son desplazados, la vida se abre en su vulnerabilidad. ¿Qué otro significado adquiere «vivir» a la luz de esta experiencia? En términos ontológicos, la vulnerabilidad muestra que el Ser no es una sustancia autosuficiente, sino que siempre ser es relación con Otros. Ser en relación, ser interdependiente, implican una apertura, un estar expuesto a algo que no se es. Algo que no se es y que sin embargo constituye aquello que somos. Desde aquí, puede afirmarse que la vida es inestable, está inacabada: no hay presencia absoluta. Judith Butler lo explica del siguiente modo:

Los cuerpos empiezan a existir y dejan de existir: como organismos físicamente persistentes que son, están sujetos a incursiones y enfermedades que ponen en peligro la posibilidad del simple persistir. Éstos son unos rasgos necesarios de los cuerpos -no pueden «ser» pensados sin su finitud y dependen de lo que hay «fuera de sí mismos» para sostenerse-, unos rasgos que pertenecen a la estructura fenomenológica de la vida corporal. Vivir es siempre vivir una vida que se halla en peligro desde el principio y que puede ser puesta en peligro o eliminada de repente desde el exterior y por razones que no siempre están bajo el control de uno» ${ }^{32}$.

Por último, la experiencia de la vulnerabilidad pone en evidencia que la vida pueda tener lugar sin el trabajo que permite sostener los cuerpos física y emocionalmente. Aquí se revela la interdependencia en su dimensión material. Tanto la inversión ontológica señalada como esta dimensión material proporcionan un punto de vista privilegiado para comprender que no hay vida posible sin los otros -los otros no humanos también- y recuperar el sentido prioritario de la dimensión común de la vida. Es importante notar que esta inversión ontológica -los cuerpos dependen de algo que no son ellos mismos- cuestiona los preceptos asociados a la modernidad -autosuficiencia, dominio, desarrollo-. De modo que esta ontología de los cuerpos en relación puede constituir un interesante punto de partida para repensar los presupuestos de la modernidad (y, por tanto, la crisis civilizatoria mencionada más arriba).

No obstante, hay que señalar que reconocer la dimensión común de la vida no implica que nos encontremos con una realidad buena o transformadora per se. Al respecto, surgen dos interrogantes. La vida no es una realidad dada, no se trata de un concepto estable, acabado y, por ello, su contenido resulta variable. Desde aquí, cabe preguntar por su articulación histórica: ¿cómo se organiza hoy la vida, aquellos marcos de inteligibilidad cultural que, como dice Judith Butler ${ }^{33}$, predisponen las visibilidades? Hay vidas que son dignas, otras menos y otras directamente no cuentan. ¿Cuáles son las jerarquías que se mantienen en el interior del concepto de vida que operan en la actualidad? ¿Y cuáles son las condiciones de posibilidad que las reproducen? ¿Qué vidas cuentan y cuáles son prescindibles, desechables, invisibles? ¿Qué presupuestos culturales se activan para legitimar estas desigualdades $?^{34}$. Por otro lado, el modo en el que se

32 Butler, J. (2009/2010), Marcos de guerra. Las vidas lloradas, Paidós: Madrid, p. 52.

33 Ibídem.

34 A raíz de los atentados de París, surgió un intenso debate en países no occidentales como México, éste sumido en la violencia y en la muerte permanentes: ¿Qué hacer con el malestar provocado por la importancia concedida 
resuelve la interdependencia hoy es injusto: el mundo sigue su curso, entre otras muchas cosas, gracias al trabajo de sostén de las redes comunitarias del que se responsabiliza principalmente a una parte de la población (las mujeres). Si tenemos en cuenta esta realidad, debemos preguntar: ¿Cómo organizar las sociedades para que el trabajo de cuidado no recaiga injustamente sobre aquéllas? ¿Qué construcciones de género son funcionales al sistema socioeconómico actual -una feminidad volcada sobre los otros, una masculinidad volcada sobre sí-? $?^{35}$. En este sentido, si bien es importante descubrir lo que de común ya hay en la realidad-darnos cuenta de aquellos gestos microscópicos o grandiosos que muestran los lazos que atan unas vidas con otras - también es importante redefinir con otros criterios ético-políticos en qué queremos que consista la vida común: cómo organizarla, a partir de que prioridades, en busca de qué intereses, desde que escenarios. Es decir, es necesaria una política imaginativa y creativa que acompañe a la anterior; una política desde la que debatir cómo vivir juntas y juntos. Debemos preguntar: ¿En qué consistiría una buena vida en condiciones de igualdad?

Por tanto, la política de lo común tiene una doble dimensión: como algo a descubrir y a construir, como ontología y organización social, como acontecimiento y creación, como política de la escucha y al mismo tiempo como invención. Para mantener este doble sentido, lo común no debe comprenderse como una sustancia, sino como un espacio abierto en el que la identidad plena, definitiva, se hace imposible. Aquí, cabe afirmar que es necesario dejar que la política se vea atravesada por la vulnerabilidad. Esto nos permite acercarnos al mundo de otro modo: muestra que nuestra posición es parcial y limitada. Pero, al mismo tiempo, es necesario que la vulnerabilidad se vea atravesada por la política: una palanca para reconstruir el mundo desde otros criterios ético-políticos que rompan con la exclusión y la injusticia, que permitan imaginar lo imposible. Percibir el inacabamiento del ser es la condición para no clausurar el sentido de la realidad, para no ceder a la pospolítica; es lo que permite producir desplazamientos no previstos, líneas inesperadas en los itinerarios. De esta forma, la vulnerabilidad se torna potencia, no como aquello que lo puede todo, sino como aquello que, sabiendo que no lo puede todo, es capaz de inventar nuevos sentidos de vida. Este es quizá el desafío -potente, creativo- al que nos interpela la experiencia de la dispersión contemporánea -con sus violencias y dificultades-: ¿Cómo volver a decir «nosotras» de un modo diferente?

\section{Referencias}

Agustín Puerta, M., (2003): Feminismo: Identidad personal y lucha colectiva (Análisis del movimiento feminista español en los años 1975 a 1985), Granada: Universidad de Granada.

Bhavnani, Kum-Kum y Coulson, Margaret, «Transformar el feminismo socialista. El reto del racismo», en VVAA. (2004), Otras inapropiables. Feminismos desde las fronteras, Madrid: Traficantes de sueños, pp. 51-62.

\footnotetext{
a las vidas europeas cuando las más cercanas no ocupan ni una mención en la prensa? Este texto de César Alan Ruiz que circuló por la red esos días condensa las preguntas y posibilidades para salir tanto del resentimiento como del eurocentrismo: «Nosotros podemos rezar por Francia, pero ¿quién rezará por nosotros?», en Tercera Vía: http://terceravia.mx/2015/11/nosotros-podemos-rezar-por-francia-pero-quien-rezara-por-nosotros/

35 Para el debate en torno al cuidado, no como revalorización de una cualidad femenina, sino como palanca crítica para la transformación véase Gil, Silvia L. (2011), op. cit., pp. 279 y ss.
} 
Butler, Judith (2004/2006): Deshacer el género, Barcelona: Paidós.

Butler, Judith (2009/2010): Marcos de guerra. Las vidas lloradas, Madrid: Paidós, 2010.

Butler, Judith y Scott, Joan (eds.) (1992): Feminist therize the political, New York, London: Routledge.

Casado, Elena (2003): «La emergencia del género y su resignificación en tiempos de lo “post"», Foro Interno. Anuario de teoría política, no 3, pp. 41-66.

Davis, Angela (1981/2005): Mujeres, raza y clase, Madrid: Akal.

Del Río, Sira (2004): «La crisis de los cuidados: precariedad a flor de piel», Rebelión. Disponible en https://www.rebelion.org/hemeroteca/economia/040308sira.htm

Echeverría, Bolívar (2010): «Crisis civilizatoria», en, Estudios Ecológicos, Crisis Financiera o Crisis Civilizatoria, $\mathrm{n}^{\circ}$ 6, Quito, pp. 3-10.

Eisenstein, Zillah (1980): Patriarcado feminista y feminismo socialista, Madrid: Siglo XXI.

Falcón, Lidia (1981): La razón feminista. La mujer como clase social y económica, el modo de producción doméstica, Barcelona: Fontanella.

Firestone, Sulamith (1976): La dialéctica del sexo. En defensa de la revolución feminista, Barcelona: Kairós.

Federici, Silvia (2011): El Calibán y la bruja, Traficantes de Sueños: Madrid.

Flax, Jean (1990/1995): Psicoanálisis y feminismo. Pensamientos fragmentarios, Madrid: Cátedra.

Foucault, Michel (1987): Historia de la sexualidad. 1. La voluntad de saber, Madrid: Siglo XXI.

Gil, Silvia L. (2014): Nuevos feminismos. Sentidos comunes en la dispersión, Madrid: Traficantes de Sueños.

Pineda, Empar, Olivan, Montserrat y Uría, Paloma (1985): Polémicas Feministas, Madrid: Revolución.

Millet, Kate (1970/1995): Política Sexual, Madrid: Cátedra.

Orozco, Amaia (2014): Subversión feminista de la economía. Apuntes para una reflexión sobre el conflicto capital/vida, Madrid: Traficantes de Sueños.

Precarias a la Deriva (2004): A la deriva por los circuitos de la precariedad femenina, Madrid: Traficantes de Sueños.

Rovira, Guiomar (2013): «De las redes a las plazas: la web 2.0 y el nuevo ciclo de protestas en el mundo», Acta Sociológica, Volumen 62, México: UNAM, pp. 105-134.

Scott, Joan W. (1996): «El género, una categoría útil para el análisis histórico», Lamas, Marta (comp.) (2013), El género. La construcción cultual de la diferencia sexual, México: PUEG/UNAM, pp. 265-302.

Segato, Rita Laura (2006/2013): Las nuevas formas de la guerra y el cuerpo de las mujeres, Buenos Aires: Tinta Limón.

Spivak, Gayatri (1987): In Other Worlds. Essays in Cultural Politics, Methuen, New York: Routledge.

Tubert, S. (ed.) (2003): Del sexo al género. Los equívocos de un concepto, Valencia: Universidad de Valencia.

VV.AA. (1977): Aportaciones a la cuestión femenina, Madrid: Akal.

VV.AA. (2005): Una Política de los Cuerpos, cuadernillo nº 1 , Área Cuerpo y comunicación de la Facultad de Ciencias Sociales de la Universidad de Buenos Aires. 